\title{
Detection of Melamine in Soybean Meal Using Near-Infrared Microscopy Imaging with Pure Component Spectra as the Evaluation Criteria
}

\author{
Zengling Yang, ${ }^{1}$ Lujia Han, ${ }^{1}$ Chengte Wang, ${ }^{1}$ Jing Li, ${ }^{1,2}$ Juan A. Fernández Pierna, ${ }^{3}$ \\ Pierre Dardenne, ${ }^{3}$ and Vincent Baeten ${ }^{3}$ \\ ${ }^{1}$ College of Engineering, China Agricultural University, Haidian District, Beijing 100083, China \\ ${ }^{2}$ Engineering College, Jiangxi Agricultural University, Nanchang 330045, China \\ ${ }^{3}$ Valorisation of Agricultural Products Department, Walloon Agricultural Research Centre (CRA-W), Henseval Building, \\ 24 Chaussée de Namur, 5030 Gembloux, Belgium
}

Correspondence should be addressed to Lujia Han; hanlj@cau.edu.cn

Received 27 July 2016; Accepted 30 August 2016

Academic Editor: Antonio A. Dos Santos

Copyright (C) 2016 Zengling Yang et al. This is an open access article distributed under the Creative Commons Attribution License, which permits unrestricted use, distribution, and reproduction in any medium, provided the original work is properly cited.

\begin{abstract}
Soybean meal was adulterated with melamine with the purpose of boosting the protein content for unlawful interests. In recent years, the near-infrared (NIR) spectroscopy technique has been widely used for guaranteeing food and feed security for its fast, nondestructive, and pollution-free characteristics. However, there are problems with using near-infrared (NIR) spectroscopy for detecting samples with low contaminant concentration because of instrument noise and sampling issues. In addition, methods based on NIR are indirect and depend on calibration models. NIR microscopy imaging offers the opportunity to investigate the chemical species present in food and feed at the microscale level (the minimum spot size is a few micrometers), thus avoiding the problem of the spectral features of contaminants being diluted by scanning. The aim of this work was to investigate the feasibility of using NIR microscopy imaging to identify melamine particles in soybean meal using only the pure component spectrum. The results presented indicate that using the classical least squares (CLS) algorithm with the nonnegative least squares (NNLS) algorithm, without needing first to develop a calibration model, could identify soybean meal that is both uncontaminated and contaminated with melamine particles at as low a level as $50 \mathrm{mg} \mathrm{kg}^{-1}$.
\end{abstract}

\section{Introduction}

Soybean meal is one of the most important feed raw materials and one of the main ingredients in compound feed because it has a complete protein profile. In the past decade, the price of soybean meal has tripled (http://faostat3. fao.org/home/index.html). The price is dictated by the protein content: the higher the content, the higher the price. There have been recent cases of soybean meal being adulterated with melamine (1,3,5-triazine-2,4,6-triamine) in order to boost the protein content [1]. There have also been cases where it was suspected that soybean meal had been contaminated with low melamine levels. The reference methods (wet chemistry) usually are time-consuming and expensive, cause damage to the sample, and need chemical reagent [2-5]. So there is a real need for fast, nondestructive, and automatically controlled screening methods that will guarantee quality and security.

Near-infrared (NIR) spectroscopy is widely used in this context because it is a rapid, nondestructive, and nonpolluting method that requires minimum or no sample preparation [6]. Applications vary from sample chemical composition to detecting adulteration or contaminant ingredients in raw materials and compound feed [7, 8]. Many studies have investigated the feasibility of using NIR to detect melamine [9-14], but there are still some problems here when it comes to testing samples with low melamine content because of the instrument noise and sampling design error $[15,16]$. NIR can 


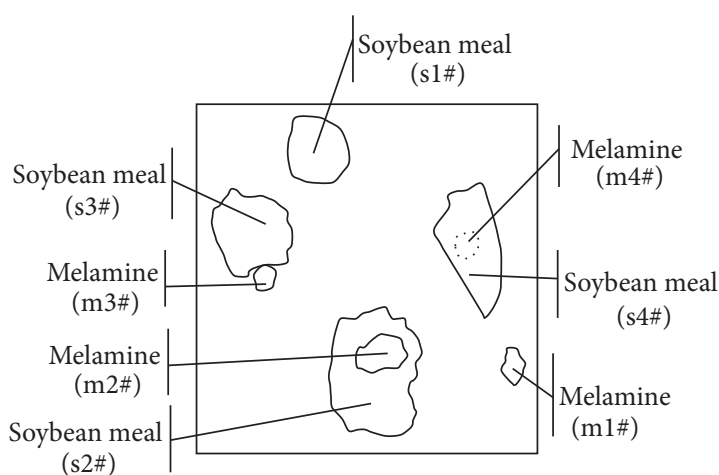

(a)

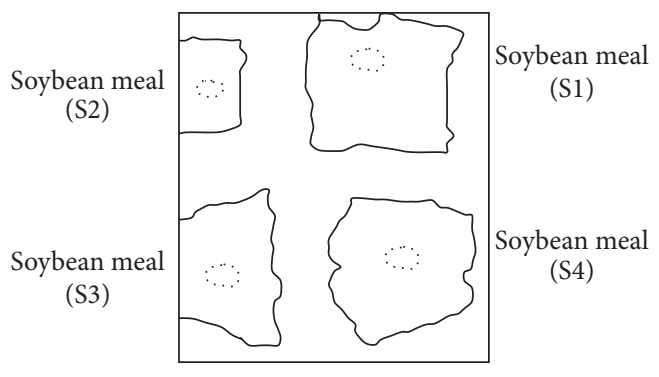

(b)

FIgURE 1: Experimental sample: (a) Set A-1; (b) Set A-2, melamine: line of dashes.

only acquire the spectra information but cannot provide the spatial information of the sample. NIR microscopy (NIRM) which combines NIR and digital images together is able to collect the spectrum of individual particles (the minimum spot size is a few micrometers) from samples [17]. With the development of a high-precision $X-Y$ motion stage, NIRM imaging is obtained by successively measuring spectra while the sample is repositioned in the $X$ and $Y$ spatial dimensions. Thus, the technique offers an opportunity to explore not only what kinds of chemical species are present at the microscale level, but also where they might be present [18].

NIRM imaging is a type of NIR imaging and has better spatial resolution. In the past decade, NIR imaging has become a powerful analytical tool for detecting contaminants and defects in agrofood products [19-25]. For feed products, several investigations have been conducted on the feasibility of using NIRM to detect, identify, and quantify processed animal byproducts [26-30] and on using NIR imaging for the complete screening of compound feeds [31].

The aim of this study was to investigate the feasibility of using NIRM imaging to identify melamine particles in soybean meal. The classical least squares (CLS) algorithm with the nonnegative least squares (NNLS) algorithm was used for the analysis of soybean meal adulterated with melamine.

\section{Materials and Methods}

2.1. Experimental Design. A total of 20 soybean meal samples were collected from various feed manufacturers and were ground to pass through a $0.5 \mathrm{~mm}$ sieve. And 3 melamine samples were bought from three chemical reagent companies, with $99 \%$ of the particles being less than $0.25 \mathrm{~mm}$ (analytical reagent, $\mathrm{C}_{3} \mathrm{H}_{6} \mathrm{~N}_{6}$ content certified by the company $\geq 99.5 \%$ ). For this study, three sets of samples were used. Set A was prepared artificially in order to develop a method without the need to create the calibration model. Set B was prepared using representative matrixes to validate the reliability and robustness of the method. Set C was prepared with low melamine content in order to investigate the sensitivity of the method.
2.1.1. Experimental Sample: Set A. Samples were artificially prepared on Teflon Spectralon using soybean meal and melamine particles (Set A-1, Figure 1(a)): a melamine particle (m2\#) was placed on top of a soybean meal particle (s2\#); a melamine particle (m4\#) was placed under a soybean meal particle (s4\#); a melamine particle (m3\#) and a soybean meal particle (s3\#) were clustered together; a single melamine particle $(\mathrm{ml} \#)$ was used alone; and a single soybean meal particle (s1\#) was used alone.

If a melamine particle is placed under a soybean meal particle, the thickness of the latter would affect the detection of the melamine particle. In order to study how this thickness affected the method, other samples were artificially prepared with different soybean meal thicknesses (Set A-2, Figure 1(b)). S1, S2, S3, and S4 relate to soybean meal that was about $30,50,100$, and $110 \mu \mathrm{m}$ thick, respectively.

2.1.2. Experimental Sample: Set B. For Set B, using 20 soybean meal and 3 melamine samples, 20 sample mixtures contaminated with $5,10,25$, and $50 \mathrm{~g} \mathrm{~kg}^{-1}$ of melamine, respectively, with five replicate samples for each melamine content level, were prepared with a mixer (REAX 20/8; Heidolph, Schwabach, Germany) in the laboratory (Table 1). In order to achieve a homogeneous distribution of melamine in the soybean meal, a stepwise dilution procedure was applied to ensure that in each dilution step the ratio of the two materials to be mixed did not exceed a factor of 3 [32].

2.1.3. Experimental Sample: Set C. As shown in Table 1, 4 sample mixtures contaminated with 1,000, 500, 100, and $50 \mathrm{mg} \mathrm{kg}^{-1}$ of melamine, respectively, were prepared in the laboratory using 4 soybean meal and 3 melamine samples.

2.2. Data Acquisition. All the samples (Set A, Set B, Set C, and 20 pure soybean meal and 3 pure melamine samples) were analyzed using a NIRM imaging system (Spotlight400, Perkin Elmer), with 16 spectra being acquired simultaneously from the line detector. The detector in this instrument is a mercury cadmium telluride ( $\mathrm{HgCdTe}$ or MCT). The spatial resolution of scanning is $25 \times 25 \mu \mathrm{m}$ and the spectral resolution is 
TABLE 1: Description of the samples Set B and Set C.

\begin{tabular}{|c|c|c|c|c|c|}
\hline \multirow{2}{*}{$\begin{array}{l}\text { Soybean meal } \\
\text { sample number }\end{array}$} & \multirow{2}{*}{$\begin{array}{c}\text { Melamine } \\
\text { sample number }\end{array}$} & \multicolumn{2}{|c|}{ Set B } & \multicolumn{2}{|c|}{ Set $\mathrm{C}$} \\
\hline & & Sample number & Melamine $\left(\mathrm{g} \mathrm{kg}^{-1}\right)$ & Sample number & Melamine $\left(\mathrm{mg} \mathrm{kg}^{-1}\right)$ \\
\hline Soy 1 & Mel 1 & Set B1 & 5 & Set $\mathrm{Cl}$ & 1,000 \\
\hline Soy 2 & Mel 2 & Set B2 & 5 & Set C2 & 500 \\
\hline Soy 3 & Mel 3 & Set B3 & 5 & Set C3 & 100 \\
\hline Soy 4 & Mel 1 & Set B4 & 5 & Set C4 & 50 \\
\hline Soy 5 & Mel 2 & Set B5 & 5 & l & l \\
\hline Soy 6 & Mel 3 & Set B6 & 10 & l & I \\
\hline Soy 7 & Mel 1 & Set B7 & 10 & I & l \\
\hline Soy 8 & Mel 2 & Set B8 & 10 & l & I \\
\hline Soy 9 & Mel 3 & Set B9 & 10 & I & I \\
\hline Soy 10 & Mel 1 & Set B10 & 10 & I & I \\
\hline Soy 11 & Mel 2 & Set B11 & 25 & I & I \\
\hline Soy 12 & Mel 3 & Set B12 & 25 & I & l \\
\hline Soy 13 & Mel 1 & Set B13 & 25 & 1 & I \\
\hline Soy 14 & Mel 2 & Set B14 & 25 & I & I \\
\hline Soy 15 & Mel 3 & Set B15 & 25 & I & I \\
\hline Soy 16 & Mel 1 & Set B16 & 50 & 1 & I \\
\hline Soy 17 & Mel 2 & Set B17 & 50 & I & I \\
\hline Soy 18 & Mel 3 & Set B18 & 50 & 1 & I \\
\hline Soy 19 & Mel 1 & Set B19 & 50 & I & I \\
\hline Soy 20 & Mel 2 & Set B20 & 50 & 1 & 1 \\
\hline
\end{tabular}

$32 \mathrm{~cm}^{-1}$. Ratio spectra $\left(R=R_{\text {sample }} / R_{\text {teflon }}\right)$ were collected using a Teflon Spectralon (Spectralon ${ }^{\circledR}$ Targets, Labsphere, Inc., North Sutton, New Hampshire) as the reflectance standard and then converted into absorbance $(A)$ by $A=$ $\log _{10}(1 / R)$. Each spectrum was the average of four scans across the wavenumber range of 7,808-4,000 $\mathrm{cm}^{-1}$.

One image (an area of $8.75 \times 8.75 \mathrm{~mm}$ coupled with $350 \times$ 350 pixels; 122,500 spectra) was scanned for each of Set B and Set C (samples with 1,000, 500, and $100 \mathrm{mg} \mathrm{kg}^{-1}$ melamine), respectively. In Set C, four images of samples with $50 \mathrm{mg} \mathrm{kg}^{-1}$ melamine were scanned, because it was more difficult to identify melamine particles at low concentrations.

One image (an area of $1.25 \times 1.25 \mathrm{~mm}$ coupled with $50 \times$ 50 pixels; 2,500 spectra) was scanned for each of the 20 pure soybean meal and 3 pure melamine samples.

\subsection{Data Analysis}

2.3.1. Preprocessing. The main purpose of preprocessing was to remove spectral and spatial artifacts such as rough surfaces, optic effects, and detector noise. The NIRM imaging data cube and the pure component spectra were both preprocessed by applying a first derivative using the SavitzkyGolay algorithm with a five-point filter width and a degree 2 polynomial [33]. The noisy part at the end of the spectra was removed by reducing the spectral range to between 7,300 and $4,100 \mathrm{~cm}^{-1}$.
2.3.2. Chemometric Tools. The classical least squares (CLS) algorithm was used to extract melamine distribution maps from whole wavelengths $[34,35]$. This algorithm is a suitable method involving minimizing the sum of squared residuals in order to predict concentrations using reference spectra only. It was based on the assumption that the absorbance spectra from a pixel in NIRM imaging can be viewed as the weighted sum of the absorbance of each pure component spectrum constituting the sample, as well as the experimental noise. Initially, the data cube $(x \times y \times \lambda)$ was unfolded into a two-dimensional matrix $X=(x y \times \lambda)$. Matrix $X$ was then decomposed as follows:

$$
X=C S^{T}+E,
$$

where $S^{T}$ represents the pure component signals; $C$ is the relative concentration matrix; and $E$ is the error matrix.

$C$ was estimated by the pseudoinverse $C=X S\left(S^{t} S\right)^{-1}$ using the nonnegative least squares (NNLS) algorithm. The concentration of melamine and soybean meal, respectively, was then calculated as follows [36]:

$$
\begin{aligned}
& C_{\text {mel }}=1000 \times \frac{\sum_{i=1}^{n} C_{i}}{\left(\sum_{i=1}^{n} C_{i}+\sum_{j=1}^{n} C_{j}\right)}, \\
& C_{\text {soy }}=1000 \times \frac{\sum_{j=1}^{n} C_{j}}{\left(\sum_{i=1}^{n} C_{i}+\sum_{j=1}^{n} C_{j}\right)},
\end{aligned}
$$


where $C_{\mathrm{mel}}\left(\mathrm{g} \mathrm{kg}^{-1}\right)$ is the melamine concentration of sample; $C_{i}$ is the melamine concentration of each pixel in the NIRM image predicted by CLS; $C_{j}$ is the soybean meal concentration of each pixel in the NIRM image predicted by CLS; $n$ is the number of pixels in one NIRM image; and $C_{\text {soy }}\left(\mathrm{g} \mathrm{kg}^{-1}\right)$ is the soybean meal concentration of the sample.

All $C_{i}$ or $C_{j}$ values formed a chemical image in which higher pixel intensity reflected higher target concentration. Matlab $^{\circledR}$ (The MathWorks, http://www.mathworks.com/) and the PLS Toolbox (Eigenvector Research, http://www. eigenvector.com/) were used to perform this analysis.

\section{Results and Discussion}

3.1. Soybean Meal and Melamine Component Spectra. The melamine reference spectrum was obtained by averaging all the pixel spectra of 3 pure melamine images, and the soybean meal reference spectrum was obtained by averaging all the pixel spectra of 20 pure soybean meal images (Figure 2). Melamine is a triazine heterocyclic organic compound, composed of nitrogen heterocyclic rings and $-\mathrm{NH}_{2}$. The NIR region offers a special advantage in the measurement of the primary amine $\mathrm{NH}_{2}$ group because of a unique combination band [37]. Melamine has three strong characteristic peaks in the $6,900-6,450 \mathrm{~cm}^{-1}$ range, especially near $6,805 \mathrm{~cm}^{-1}$, which is the $\mathrm{N}-\mathrm{H}$ combination band $(\nu \mathrm{N}-\mathrm{H}$ asymmetric and $v \mathrm{~N}-\mathrm{H}$ symmetric combination) from primary amides. Figure 2 showed that melamine has a distinctive spectral feature compared with soybean meal, facilitating the identification of melamine particles present in mixtures.

3.2. Soybean Meal Analysis Using CLS. Table 2 showed the minimum $C_{j}$ of 20 soybean meal samples which were calculated by CLS. Meanwhile, the mean value of the minimum values of $C_{j}$ is 0.8822 and the standard deviation is 0.0484 . In consideration of the conciseness and effectiveness, the liminal value of soybean meal's $C_{j}$ was 0.8 .

3.3. Melamine Detection Using CLS. Figure 3 showed the detection results of Set A samples using CLS algorithm. Figure 3(a) was a soybean meal image produced by CLS. Four soybean meal particles (s1\#, s2\#, s3\#, and s4\#) could be correctly identified. Figure 3 (b) showed a melamine image produced by CLS. CLS could detect the presence of melamine $\mathrm{m} 1 \#, \mathrm{~m} 2 \#$, and $\mathrm{m} 3 \#$, but not $\mathrm{m} 4 \#$ which was placed under a $150 \mu \mathrm{m}$ thick soybean meal particle. In order to investigate the effect of soybean meal thickness on the detection of melamine under the soybean meal particle using the CLS algorithm, an image of sample Set A-2 was obtained and analyzed using CLS. When the soybean meal was $30 \mu \mathrm{m}$ and $50 \mu \mathrm{m}$ thick, CLS could detect the presence of melamine, but it could not do so if the melamine was under soybean meal that was thicker than $100 \mu \mathrm{m}$. In addition, the signal of the melamine under soybean meal that was $50 \mu \mathrm{m}$ thick was weaker than the signal when the thickness was $30 \mu \mathrm{m}$, illustrating the difficulty of detecting the presence of melamine when melamine particles were embedded in soybean meal particles.
TABLE 2: The minimum $C_{j}$ of 20 soybean meal samples calculated by CLS.

\begin{tabular}{lc}
\hline Sample number & Min of $C_{j}$ \\
\hline Soy 1 & 0.9387 \\
Soy 2 & 0.8099 \\
Soy 3 & 0.9317 \\
Soy 4 & 0.9358 \\
Soy 5 & 0.9278 \\
Soy 6 & 0.7671 \\
Soy 7 & 0.8276 \\
Soy 8 & 0.9322 \\
Soy 9 & 0.9008 \\
Soy 10 & 0.8214 \\
Soy 11 & 0.8721 \\
Soy 12 & 0.9315 \\
Soy 13 & 0.9084 \\
Soy 14 & 0.8611 \\
Soy 15 & 0.8941 \\
Soy 16 & 0.8941 \\
Soy 17 & 0.9036 \\
Soy 18 & 0.8479 \\
Soy 19 & 0.8702 \\
Soy 20 & 0.8677 \\
\hline
\end{tabular}

Sample Set B containing 20 contaminated samples were analyzed using the CLS algorithm and the results were shown in Table 3. The concentrations of melamine calculated by CLS were $0.84 \pm 0.30,3.51 \pm 0.75,8.17 \pm 1.21$, and $32.23 \pm 4.33 \mathrm{~g} \mathrm{~kg}^{-1}$ for the $5,10,25$, and $50 \mathrm{~g} \mathrm{~kg}^{-1}$ melamine content samples, respectively. The melamine in the 20 mixture samples was successfully detected. Although the melamine concentration was underestimated by CLS, there was a good linear relationship between the predicted and real values (predicted values $=0.57 \times$ real values, $R^{2}=0.90$ ). Particle size, surface roughness, and density of the sample spread on a Teflon Spectralon surface in a single layer were important factors in quantifying melamine correctly. It is also likely that the melamine concentration was underestimated because of the difficulty in detecting melamine if the particles were under or tightly embedded in the soybean meal particles, as shown in sample Set A.

The pixel spectra corresponding to the $C_{i}$ maximum of melamine for the 20 sample mixtures are shown in Figure 4. These melamine spectral characteristics indicated reliable extraction by CLS. In addition, the results showed that NIRM imaging data combined with the CLS algorithm could provide a visual melamine distribution map (Figure 5) for the analyst, which could not be done by NIR because the spatial information is lost. 


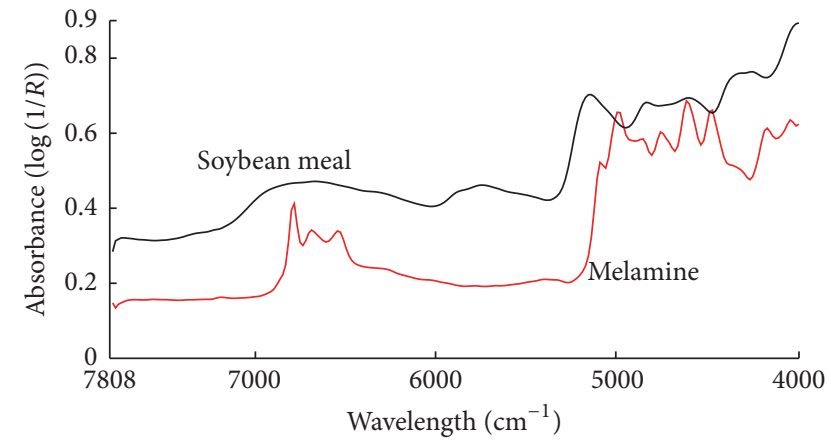

(a)

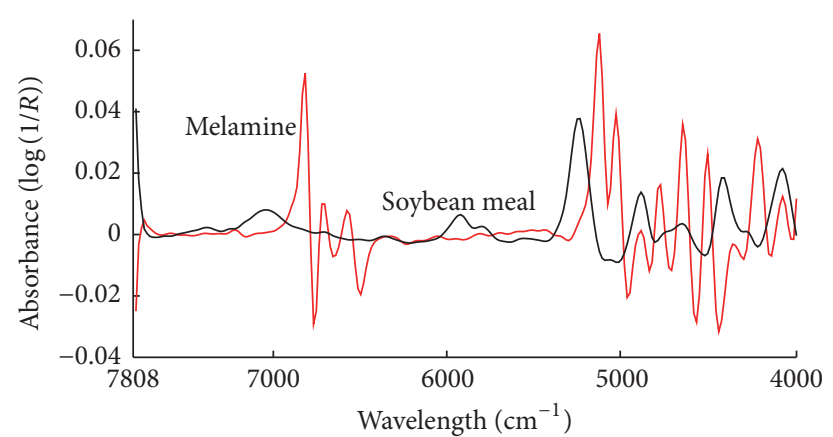

(b)

FIGURE 2: Average spectrum of soybean meal and melamine particles: raw spectra (a) and first derivative spectra (b).

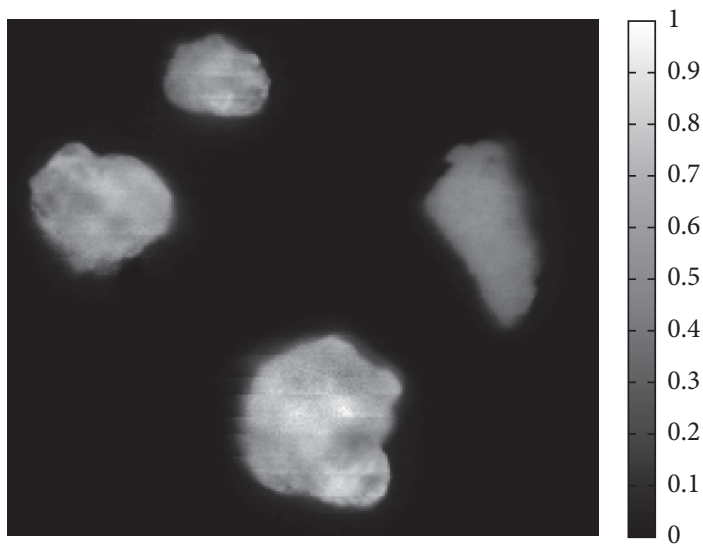

(a)

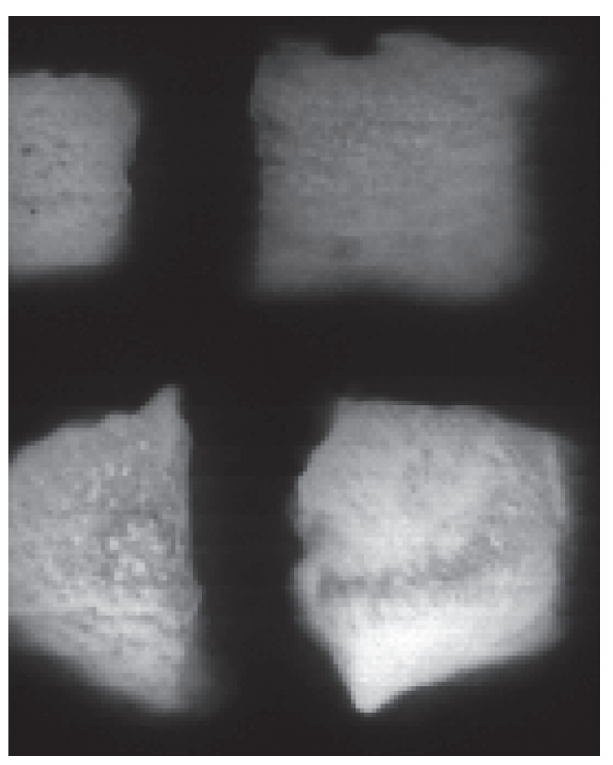

(c)

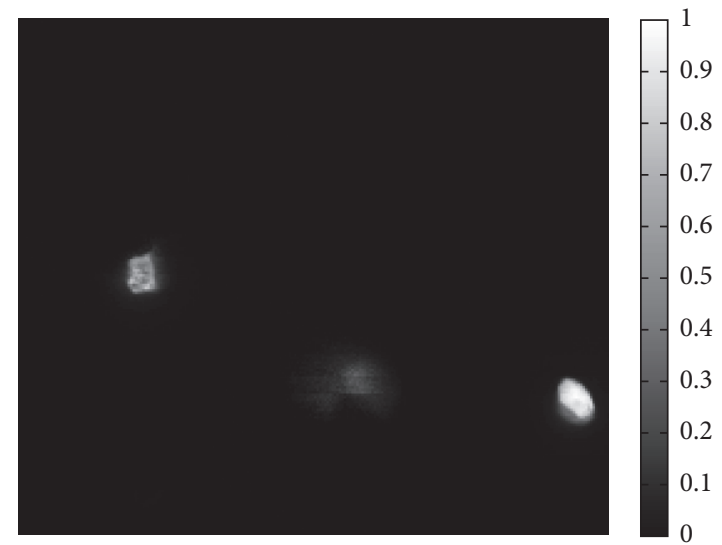

(b)
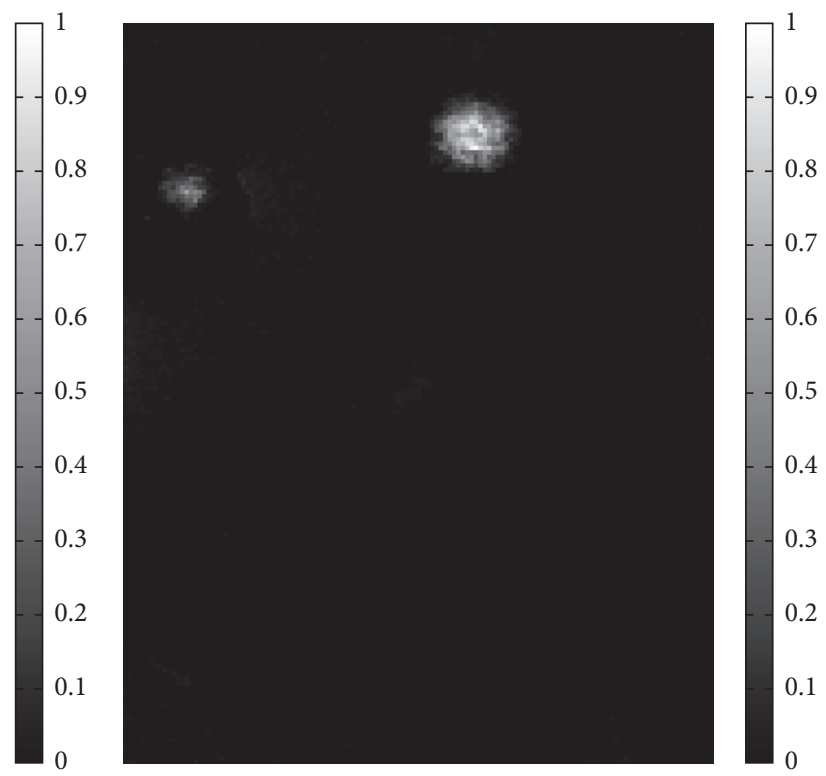

(d)

Figure 3: The detection results of soybean and melamine of Set A samples using CLS algorithm: (a) soybean image of Set A-1; (b) melamine image of Set A-1; (c) soybean image of Set A-2; (d) melamine image of Set A-2. 
TABLE 3: Discriminant results of the analysis of the Set B samples using CLS.

\begin{tabular}{|c|c|c|c|c|}
\hline \multirow{2}{*}{ Sample number } & \multirow{2}{*}{ Melamine $\left(\mathrm{g} \mathrm{kg}^{-1}\right)$} & \multicolumn{3}{|c|}{ Melamine detected } \\
\hline & & $C_{\text {mel }}\left(\mathrm{g} \mathrm{kg}^{-1}\right)$ & Max of $C_{i}$ & Number of spectra \\
\hline Set B1 & 5 & 1.16 & 1.0919 & 1,955 \\
\hline Set B2 & 5 & 1.01 & 0.7524 & 1,897 \\
\hline Set B3 & 5 & 0.92 & 0.6206 & 1,959 \\
\hline Set B4 & 5 & 0.41 & 0.5971 & 1,337 \\
\hline Set B5 & 5 & 0.67 & 0.5686 & 1,509 \\
\hline Set B6 & 10 & 3.06 & 0.6696 & 6,635 \\
\hline Set B7 & 10 & 3.27 & 0.8080 & 6,449 \\
\hline Set B8 & 10 & 3.53 & 0.8891 & 7,865 \\
\hline Set B9 & 10 & 2.91 & 0.7721 & 7,998 \\
\hline Set B10 & 10 & 4.78 & 0.9064 & 10,871 \\
\hline Set B11 & 25 & 8.54 & 0.9536 & 21,913 \\
\hline Set B12 & 25 & 7.03 & 0.5367 & 25,188 \\
\hline Set B13 & 25 & 6.74 & 0.7325 & 15,940 \\
\hline Set B14 & 25 & 9.18 & 0.8827 & 19,452 \\
\hline Set B15 & 25 & 9.35 & 0.7916 & 39,533 \\
\hline Set B16 & 50 & 37.22 & 0.9413 & 90,127 \\
\hline Set B17 & 50 & 28.71 & 0.8753 & 81,584 \\
\hline Set B18 & 50 & 34.09 & 0.5128 & 106,041 \\
\hline Set B19 & 50 & 26.78 & 0.6352 & 89,335 \\
\hline Set B20 & 50 & 34.37 & 0.6912 & 101,457 \\
\hline
\end{tabular}

Sample Set $\mathrm{C}$ was used to investigate the method's sensitivity. $C_{j}<0.8$ and $\mathrm{GH}>3$ were combined together for melamine detection in sample Set $\mathrm{C}$. The GH is the standardized Mahalanobis distance between each spectrum and average spectrum, and GH $>3$ is used to identify the outliers $[38,39]$. In this work, 480 representative spectra were picked out from the 20 pure soybean meal images. And the GH values between the target spectrum and the 480 soybean spectra were calculated to identify whether the target spectrum is soybean spectrum or not.

As shown in Figure 6, all the 1000, 500, and $100 \mathrm{mg} \mathrm{kg}^{-1}$ of melamine images had spectra out of both $\mathrm{GH}$ and $C_{j}$ liminal values. Two of four $50 \mathrm{mg} \mathrm{kg}^{-1}$ melamine images had spectra out of both $\mathrm{GH}$ and $C_{j}$ liminal values. Using $\mathrm{GH}$ and $C_{j}$ liminal values to analyze 20 pure soybean meal samples, there were also some abnormal spectra in Soy 6. The abnormal spectra detected by $C_{j}<0.8$ and $\mathrm{GH}>3$ of Set $\mathrm{C}$ and Soy 6 were shown in Figure 7. All the spectra separated from Set $\mathrm{C}$ had the melamine spectra characteristics which could be recognized by visual inspection. Meanwhile the spectra separated from Soy 6 were not similar with melamine spectrum or soybean meal average spectrum; this part of the spectra was more like fullfat soybean which could be seen in the article published by Shen et al. [39].

\section{Conclusions}

The results presented in this study showed the feasibility of the NIRM imaging with pure component spectra for the analysis of soybean meal adulterated with melamine. The minimum effective detection concentration of melamine was $50 \mathrm{mg} \mathrm{kg}^{-1}$. NIRM imaging method is a nondestructive, pollution-free, and cheaper testing technology compared with wet chemical analysis method, and it could analyze one sample within four hours. NIRM imaging combined with the CLS algorithm can successfully detect melamine in soybean meal without building the calibration model, which provided a new and feasible way for safety control of feed.

\section{Competing Interests}

The authors declare that there is no conflict of interests regarding the publication of this paper.

\section{Acknowledgments}

The research leading to these results was funded by the European Union's Seventh Framework Program (FP7/20072013) under Grant Agreement 265702 (Quality and Safety 


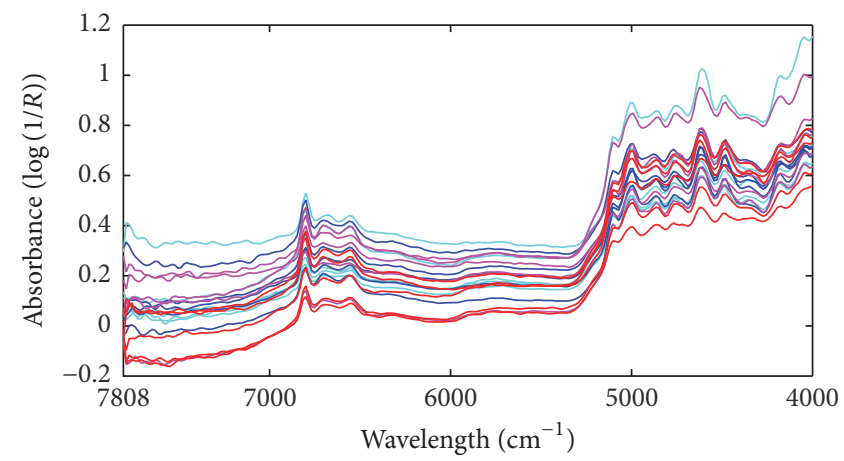

Figure 4: The pixel spectra corresponding to the $C_{i}$ maximum of melamine for Set B samples: $5 \mathrm{~g} \mathrm{~kg}^{-1}$ (cyan), $10 \mathrm{~g} \mathrm{~kg}^{-1}$ (blue), $25 \mathrm{~g} \mathrm{~kg}^{-1}$ (magenta), and $50 \mathrm{~g} \mathrm{~kg}^{-1}$ (red).

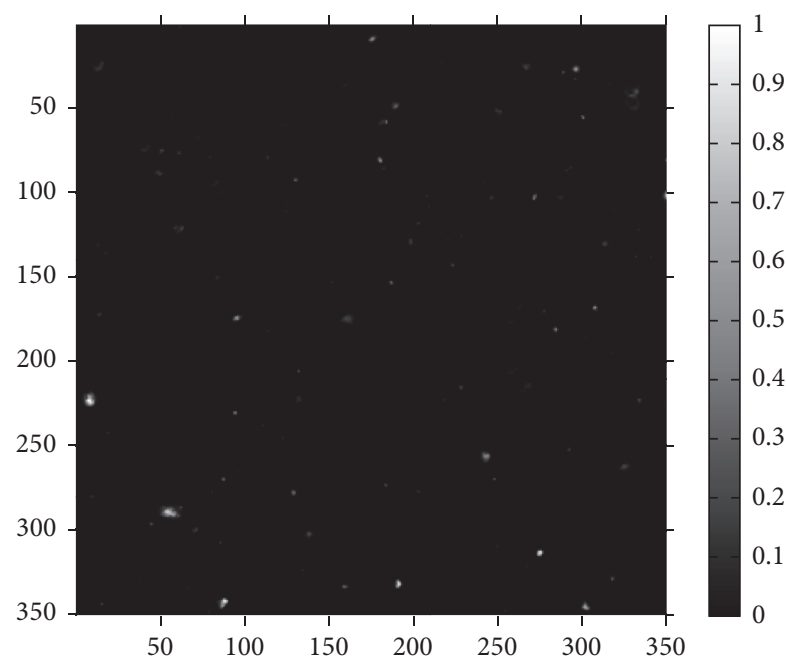

(a)

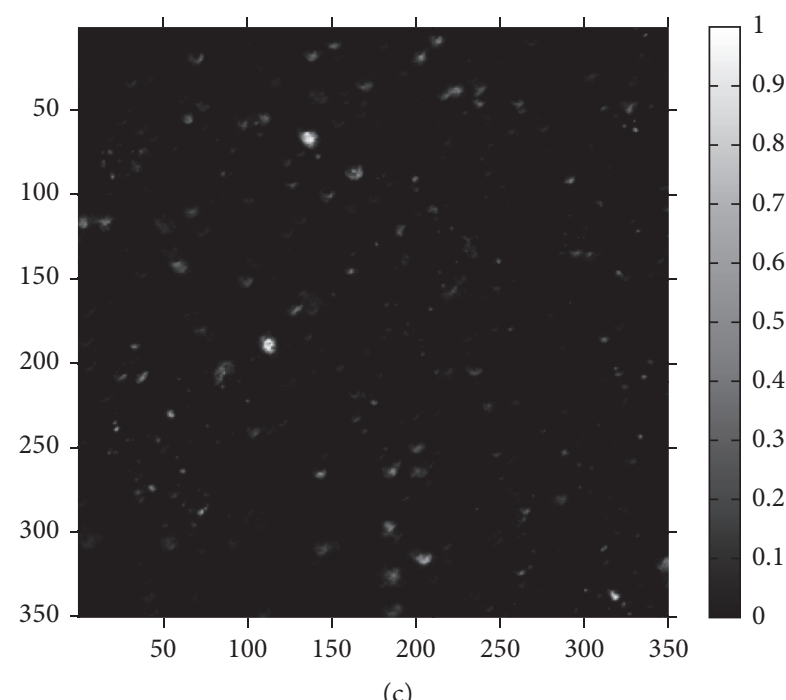

(c)

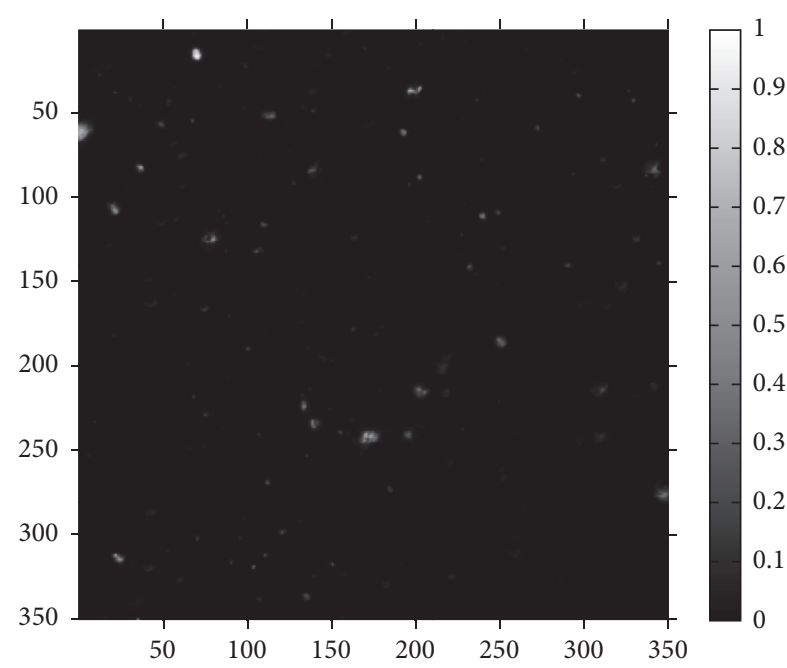

(b)

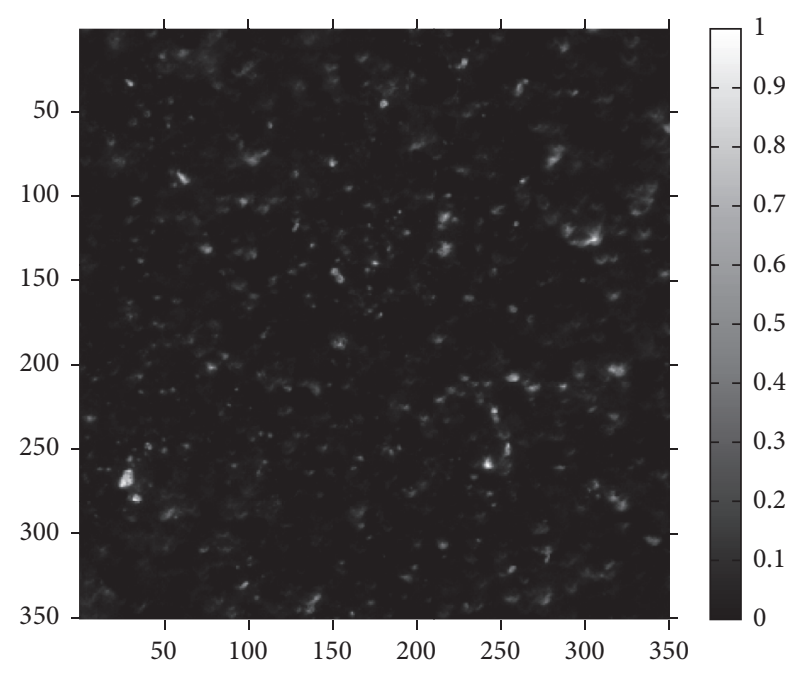

(d)

FIGURE 5: The melamine distribution map predicted by CLS applied to the NIRM imaging data. Only one sample was taken as an example of each concentration. (a), (b), (c), and (d) represent 5, 10, 25, and $50 \mathrm{~g} \mathrm{~kg}^{-1}$ of melamine, respectively. 


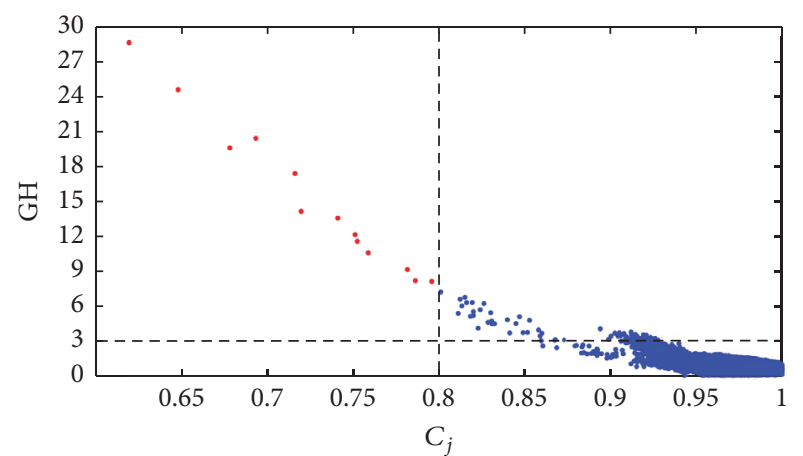

(a)

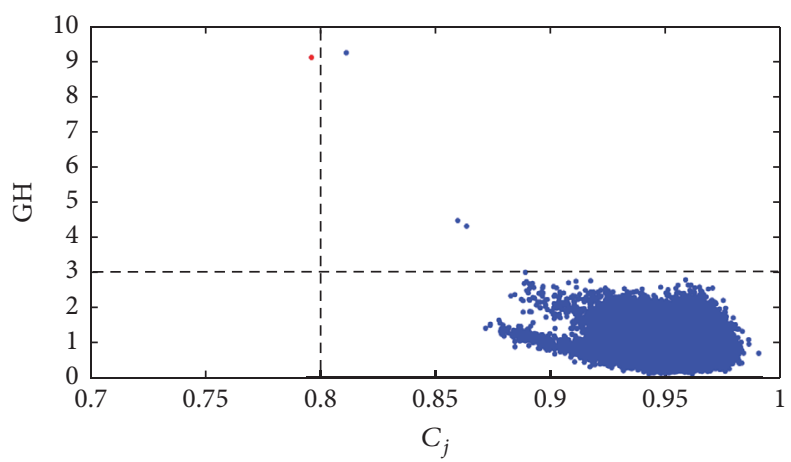

(c)

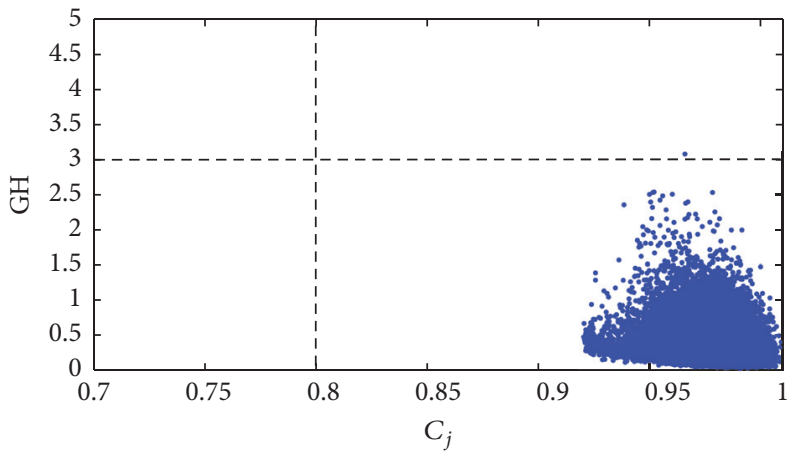

(e)

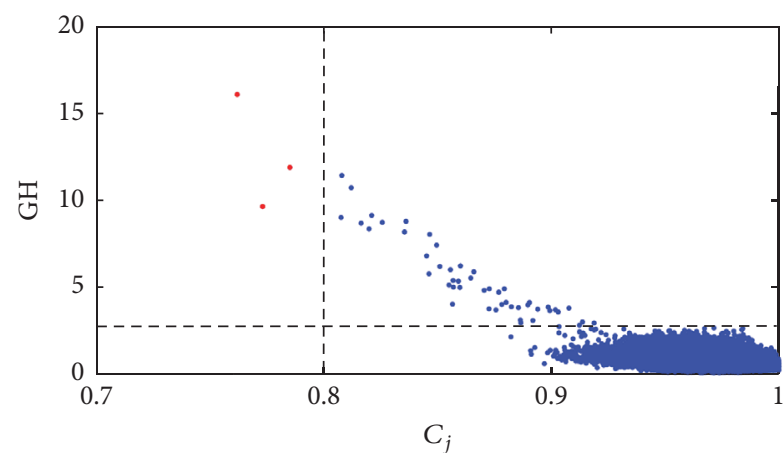

(b)

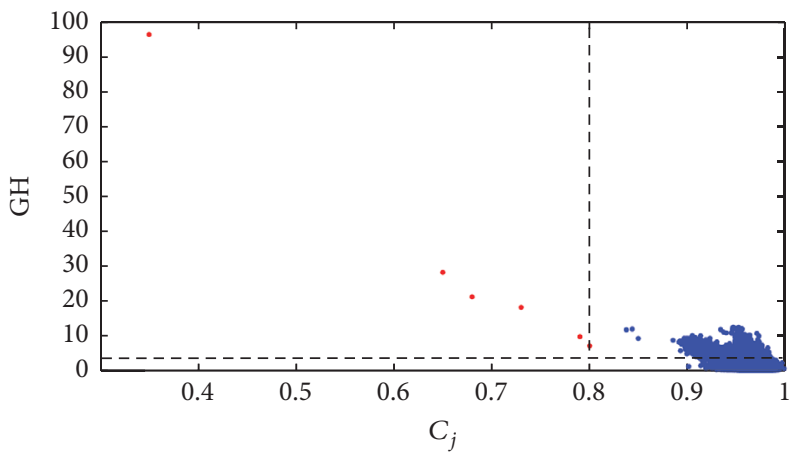

(d)

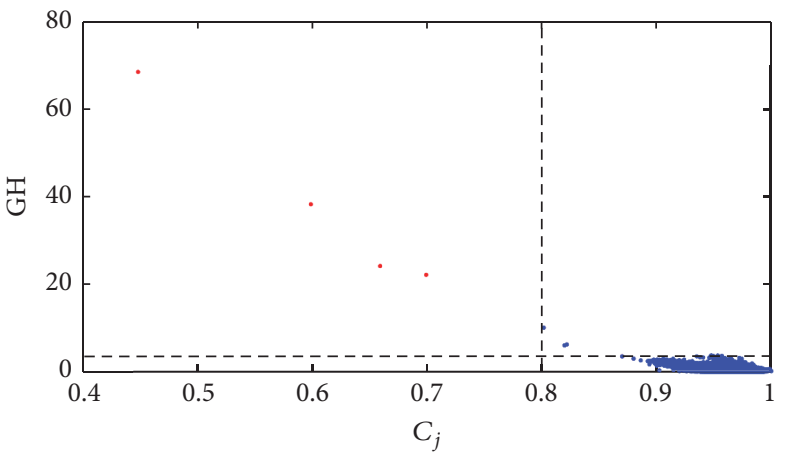

(f)

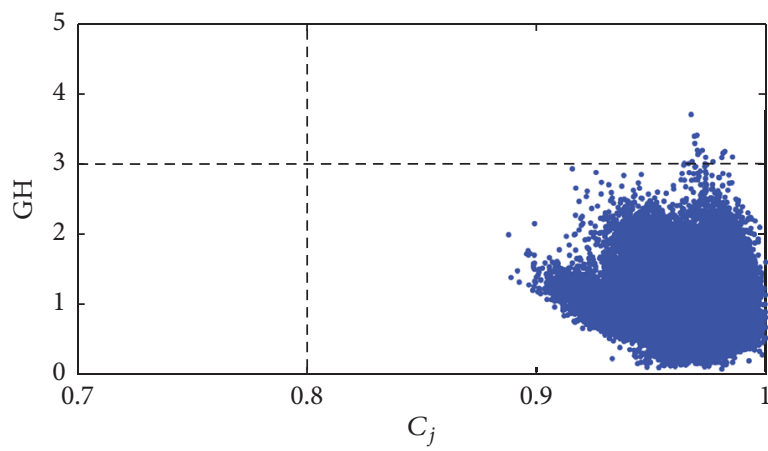

(g)

Figure 6: The $C_{j}$-GH diagram of Set C. (a), (b), and (c) represent 1000, 500, and $100 \mathrm{mg} \mathrm{kg}^{-1}$ of melamine images, while (d), (e), (f), and (g) represent four $50 \mathrm{mg} \mathrm{kg}^{-1}$ of melamine images. 


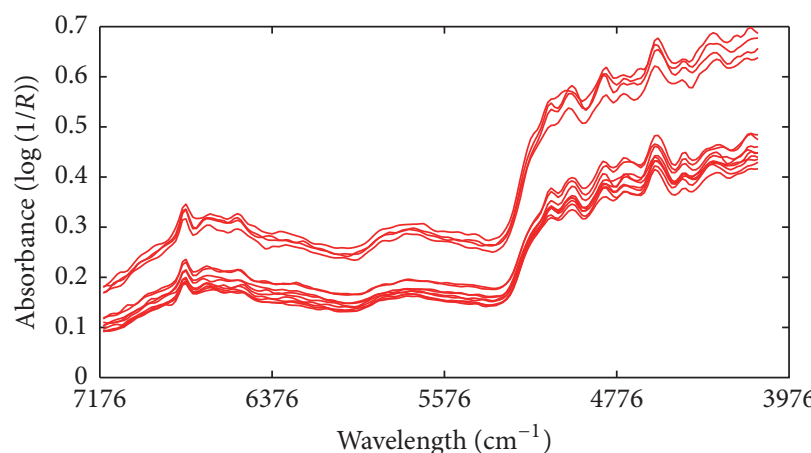

(a)

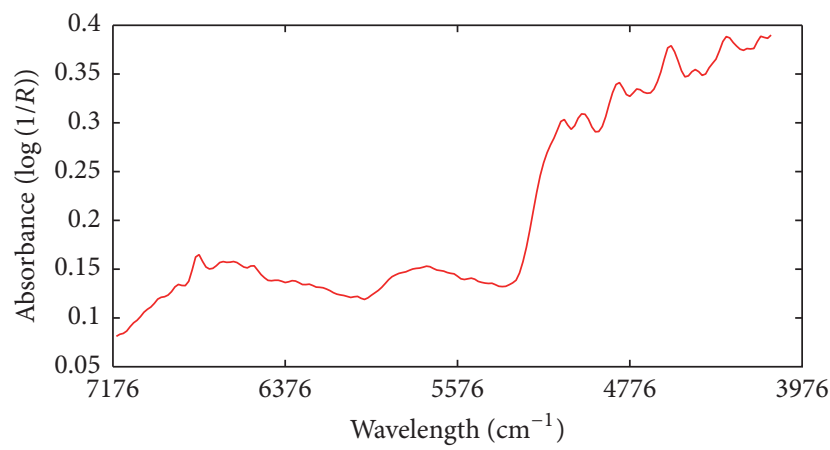

(c)

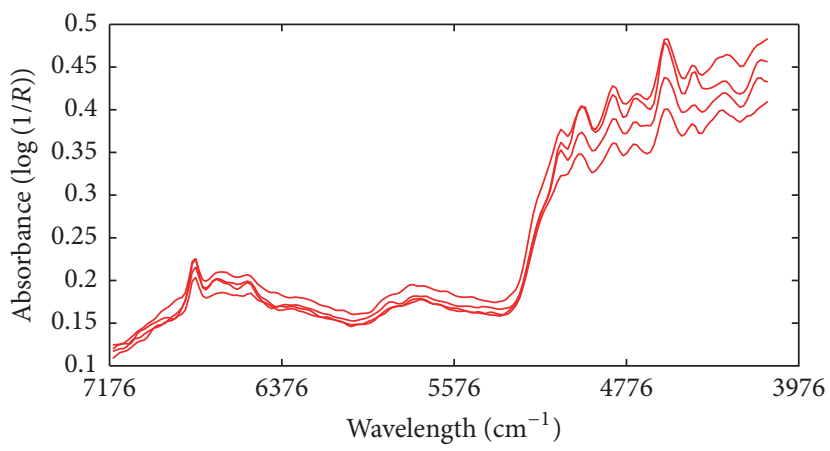

(e)

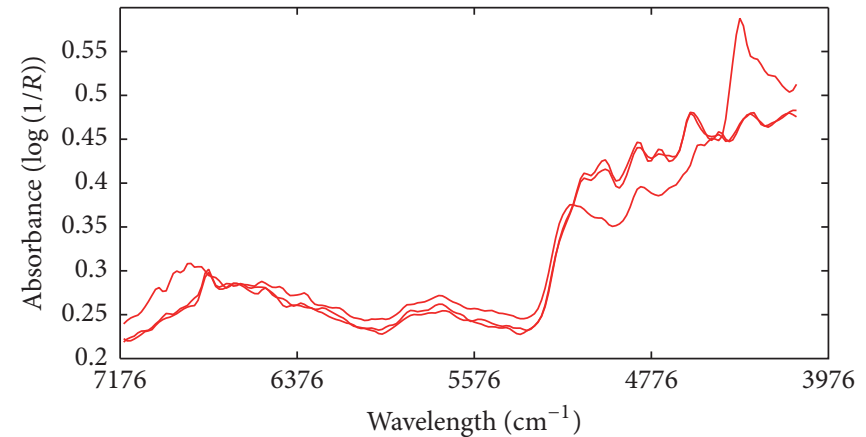

(b)

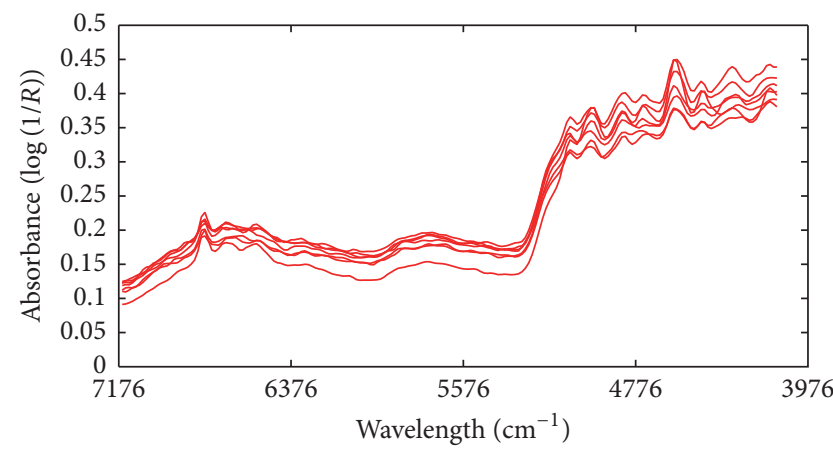

(d)

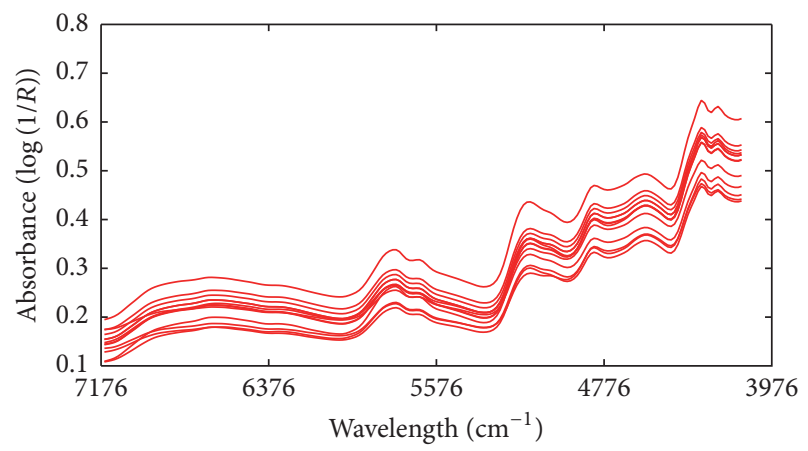

(f)

Figure 7: The spectra out of both GH and $C_{j}$ liminal values. (a), (b), and (c) represent 1000, 500, and $100 \mathrm{mg} \mathrm{kg}^{-1}$ of melamine images, (d) and (e) represent two $50 \mathrm{mg} \mathrm{kg}^{-1}$ of melamine images, and (f) represents Soy 6 image.

of Feeds and Food for Europe, QSAFFE), National Science and Technology Support Program (2014BAD08B112), Program of International S\&T Cooperation (Project no. 2015DFG32170), and the Bruxelles-Wallonie International Cooperation Project between the Walloon Agricultural Research Centre (CRA-W) in Gembloux, Belgium, and the China Agricultural University (CAU) in Beijing, China. The authors would also like to thank Jiang Xunpeng and Chen Qianrong for their help in data processing and experimental design.

\section{References}

[1] J. L. Dorne, D. R. Doerge, M. Vandenbroeck et al., "Recent advances in the risk assessment of melamine and cyanuric acid in animal feed," Toxicology and Applied Pharmacology, vol. 270, no. 3, pp. 218-229, 2013.

[2] G. Venkatasami and J. R. Sowa, "A rapid, acetonitrile-free, HPLC method for determination of melamine in infant formula," Analytica Chimica Acta, vol. 665, no. 2, pp. 227-230, 2010.

[3] L. Zhao, J. Zhao, W.-G. Huangfu, and Y.-L. Wu, "Simultaneous determination of melamine and clenbuterol in animal feeds by GC-MS," Chromatographia, vol. 72, no. 3-4, pp. 365-368, 2010.

[4] S. Squadrone, G. L. Ferro, D. Marchis et al., "Determination of melamine in feed: validation of a gas chromatography-mass spectrometry method according to 2004/882/CE regulation," Food Control, vol. 21, no. 5, pp. 714-718, 2010.

[5] S. Turnipseed, C. Casey, C. Nochetto et al., "Determination of melamine and cyanuric acid residues in infant formula using LC-MS/MS ", Laboratory Information Bulletin, vol. 4421, pp. 496-549, 2008. 
[6] L. Chen, Z. Yang, and L. Han, "A review on the use of nearinfrared spectroscopy for analyzing feed protein materials," Applied Spectroscopy Reviews, vol. 48, no. 7, pp. 509-522, 2013.

[7] V. Baeten, M. Manley, and J. A. Fernández Pierna, "Spectroscopic techniques: Fourier Transform (FT) Near Infrared spectroscopy (NIR) and microscopy (NIRM)," in Modern Techniques for Food Authentication, D.-W. Sun, Ed., pp. 117-148, Academic Press, Oxford, UK, 2008.

[8] J. A. Fernández Pierna, V. Baeten, and A. Boix, "Detection, identification and quantification of processed animal proteins in feedingstuffs," in Near Infrared Microscopy, J. S. Jorgensen and V. Baeten, Eds., pp. 81-91, Les Presses Universitaires de Namur, Namur, Belgium, 2012.

[9] C. Lu, B. Xiang, G. Hao, J. Xu, Z. Wang, and C. Chen, "Rapid detection of melamine in milk powder by near infrared spectroscopy," Journal of Near Infrared Spectroscopy, vol. 17, no. 2, pp. 59-67, 2009.

[10] L. J. Mauer, A. A. Chernyshova, A. Hiatt, A. Deering, and R. Davis, "Melamine detection in infant formula powder using near- and mid-infrared spectroscopy," Journal of Agricultural and Food Chemistry, vol. 57, no. 10, pp. 3974-3980, 2009.

[11] R. M. Balabin and S. V. Smirnov, "Melamine detection by mid- and near-infrared (MIR/NIR) spectroscopy: a quick and sensitive method for dairy products analysis including liquid milk, infant formula, and milk powder," Talanta, vol. 85, no. 1 , pp. 562-568, 2011.

[12] S. A. Haughey, S. F. Graham, E. Cancouët, and C. T. Elliott, "The application of Near-Infrared Reflectance Spectroscopy (NIRS) to detect melamine adulteration of soya bean meal," Food Chemistry, vol. 136, no. 3-4, pp. 1557-1561, 2013.

[13] S. Jawaid, F. N. Talpur, S. T. H. Sherazi, S. M. Nizamani, and A. A. Khaskheli, "Rapid detection of melamine adulteration in dairy milk by SB-ATR-Fourier transform infrared spectroscopy," Food Chemistry, vol. 141, no. 3, pp. 3066-3071, 2013.

[14] O. Abbas, B. Lecler, P. Dardenne, and V. Baeten, "Detection of melamine and cyanuric acid in feed ingredients by near infrared spectroscopy and chemometrics," Journal of Near Infrared Spectroscopy, vol. 21, no. 3, pp. 183-194, 2013.

[15] K. Norris, "Hazards with near infrared spectroscopy in detecting contamination," Journal of Near Infrared Spectroscopy, vol. 17, no. 4, pp. 165-166, 2009.

[16] V. Baeten and P. Dardenne, "Applications of near-infrared imaging for monitoring agricultural food and feed products," in Spectrochemical Analysis Using Infrared Multichannel Detectors, R. Bhargava and I. W. Levin, Eds., pp. 283-302, Blackwell, 2005.

[17] Z. Yang, C. Wang, L. Han, J. Li, and X. Liu, "Rapid screening and visual tracing of melamine in soybean meal by NIR microscopy imaging," Journal of Innovative Optical Health Sciences, vol. 7, no. 4, Article ID 1350072, 2014.

[18] F. Clarke, "Extracting process-related information from pharmaceutical dosage forms using near infrared microscopy," Vibrational Spectroscopy, vol. 34, no. 1, pp. 25-35, 2004.

[19] J. Dubois, E. Neil Lewis, F. S. Fry Jr., and E. M. Calvey, "Bacterial identification by near-infrared chemical imaging of food-specific cards," Food Microbiology, vol. 22, no. 6, pp. 577583, 2005.

[20] D. P. Ariana, R. Lu, and D. E. Guyer, "Near-infrared hyperspectral reflectance imaging for detection of bruises on pickling cucumbers," Computers and Electronics in Agriculture, vol. 53, no. 1, pp. 60-70, 2006.

[21] P. Williams, P. Geladi, G. Fox, and M. Manley, "Maize kernel hardness classification by near infrared (NIR) hyperspectral imaging and multivariate data analysis," Analytica Chimica Acta, vol. 653, no. 2, pp. 121-130, 2009.

[22] J. P. Wold, M. O'Farrell, M. Høy, and J. Tschudi, “On-line determination and control of fat content in batches of beef trimmings by NIR imaging spectroscopy," Meat Science, vol. 89, no. 3, pp. 317-324, 2011.

[23] R. Krska and M. Nielen, "Rapid detection in food and feed," Analytical and Bioanalytical Chemistry, vol. 405, no. 24, pp. 7717-7718, 2013.

[24] P. Vermeulen, J. A. Fernández Pierna, H. P. van Egmond, P. Dardenne, and V. Baeten, "Online detection and quantification of ergot bodies in cereals using near infrared hyperspectral imaging," Food Additives \& Contaminants: Part A, vol. 29, no. 2, pp. 232-240, 2012.

[25] Y. Huang, S. Min, J. Duan, L. Wu, and Q. Li, "Identification of additive components in powdered milk by NIR imaging methods," Food Chemistry, vol. 145, pp. 278-283, 2014.

[26] V. Baeten, C. Von Holst, A. Garrido, J. Vancutsem, A. M. Renier, and P. Dardenne, "Detection of banned meat and bone meal in feedstuffs by near-infrared microscopic analysis of the dense sediment fraction," Analytical and Bioanalytical Chemistry, vol. 382, no. 1, pp. 149-157, 2005.

[27] B. De la Roza-Delgado, A. Soldado, A. Martínez-Fernández et al., "Application of near-infrared microscopy (NIRM) for the detection of meat and bone meals in animal feeds: a tool for food and feed safety," Food Chemistry, vol. 105, no. 3, pp. 11641170, 2007.

[28] V. Fernández-Ibáñez, T. Fearn, A. Soldado, and B. de la Roza-Delgado, "Spectral library validation to identify ingredients of compound feedingstuffs by near infrared reflectance microscopy," Talanta, vol. 80, no. 1, pp. 54-60, 2009.

[29] D. Pérez-Marín, T. Fearn, J. E. Guerrero, and A. Garrido-Varo, "A methodology based on NIR-microscopy for the detection of animal protein by-products," Talanta, vol. 80, no. 1, pp. 48-53, 2009.

[30] O. Abbas, J. A. Fernández Pierna, A. Boix, C. Von Holst, P. Dardenne, and V. Baeten, "Key parameters for the development of a NIR microscopic method for the quantification of processed by-products of animal origin in compound feedingstuffs," Analytical and Bioanalytical Chemistry, vol. 397, no. 5, pp. 19651973, 2010.

[31] J. A. Fernández Pierna, V. Baeten, and P. Dardenne, "Screening of compound feeds using NIR hyperspectral data," Chemometrics and Intelligent Laboratory Systems, vol. 84, no. 1-2, pp. 114$118,2006$.

[32] G. Gizzi, C. von Holst, V. Baeten, G. Berben, and L. Van Raamsdonk, "Determination of processed animal proteins, including meat and bone meal, in animal feed," Journal of AOAC International, vol. 87, no. 6, pp. 1334-1341, 2004.

[33] C. Gendrin, Y. Roggo, and C. Collet, "Pharmaceutical applications of vibrational chemical imaging and chemometrics: a review," Journal of Pharmaceutical and Biomedical Analysis, vol. 48, no. 3, pp. 533-553, 2008.

[34] K. L. A. Chan, N. Elkhider, and S. G. Kazarian, "Spectroscopic imaging of compacted pharmaceutical tablets," Chemical Engineering Research and Design, vol. 83, no. 11, pp. 1303-1310, 2005.

[35] G. P. Sabin, M. C. Breitkreitz, A. M. de Souza et al., "Analysis of pharmaceutical pellets: an approach using near-infrared chemical imaging," Analytica Chimica Acta, vol. 706, no. 1, pp. 113-119, 2011. 
[36] C. Gendrin, Y. Roggo, and C. Collet, "Content uniformity of pharmaceutical solid dosage forms by near infrared hyperspectral imaging: a feasibility study," Talanta, vol. 73, no. 4, pp. 733741, 2007.

[37] L. Weyer and J. Workman Jr, Practical Guide to Interpretive Near-Infrared Spectroscopy, CRC Press, 2007.

[38] J. A. Guthrie, Robustness of NIR Calibrations for Assessing Fruit Quality, Faculty of Arts, Health and Sciences, Central Queensland University, 2005.

[39] G. Shen, X. Fan, Z. Yang, and L. Han, "A feasibility study of nontargeted adulterant screening based on NIRM spectral library of soybean meal to guarantee quality: the example of non-protein nitrogen," Food Chemistry, vol. 210, pp. 35-42, 2016. 

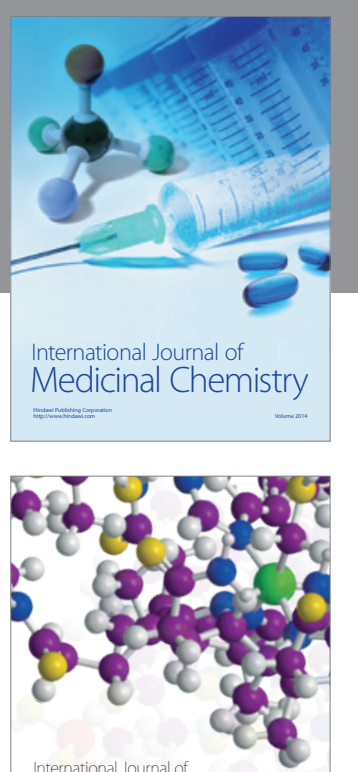

Carbohydrate Chemistry

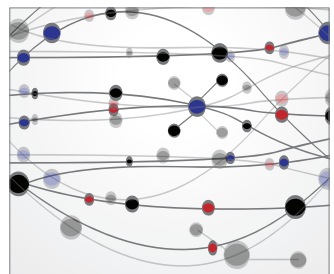

The Scientific World Journal
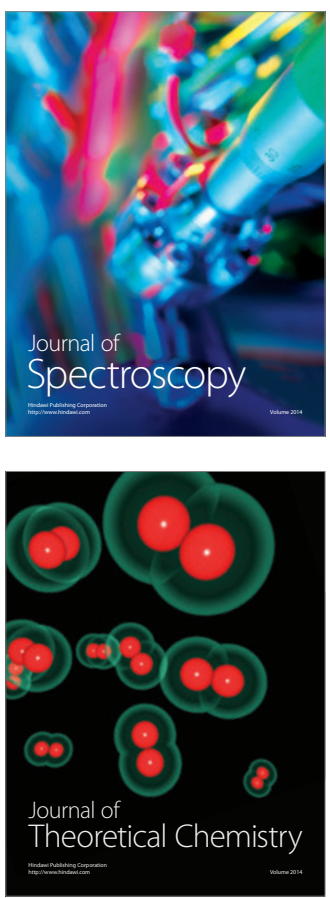
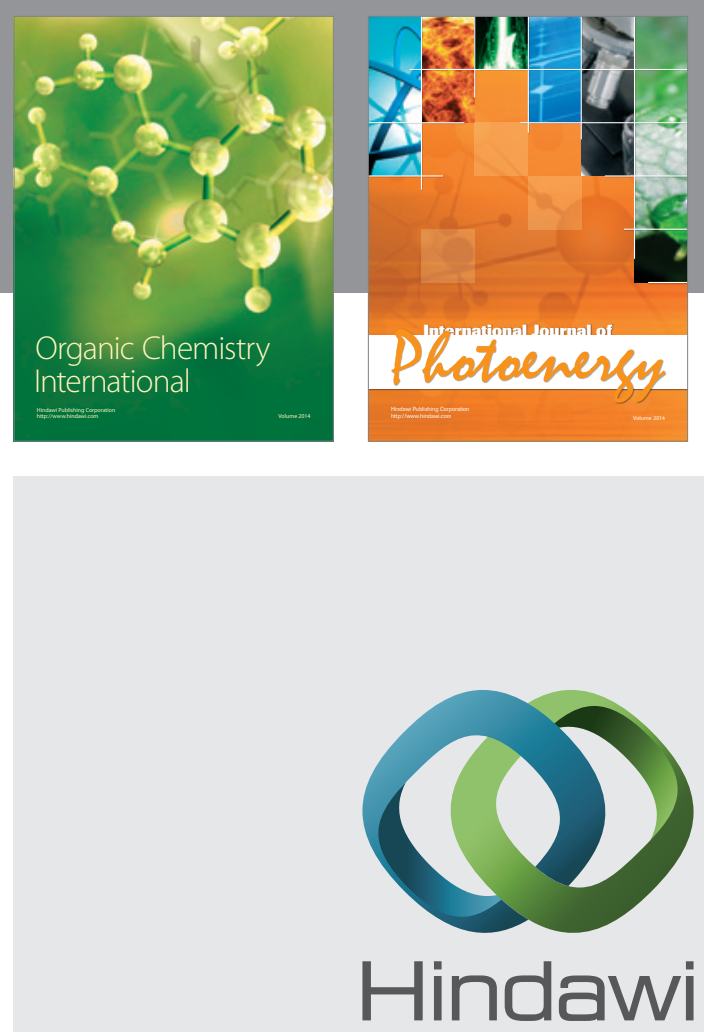

Submit your manuscripts at

http://www.hindawi.com

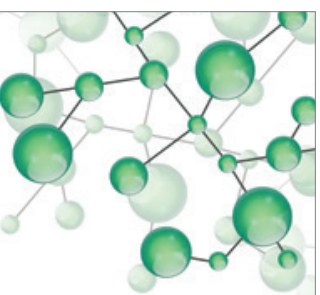

International Journal of

Inorganic Chemistry

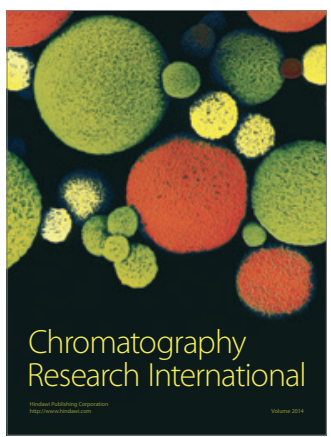

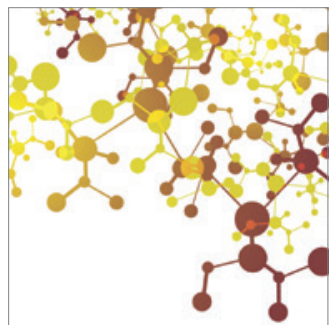

Applied Chemistry
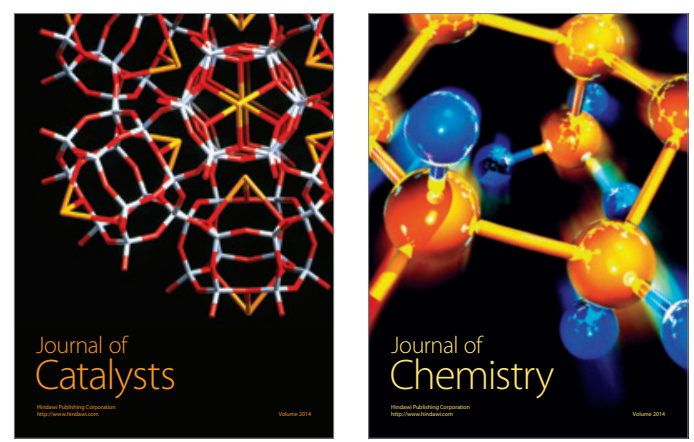
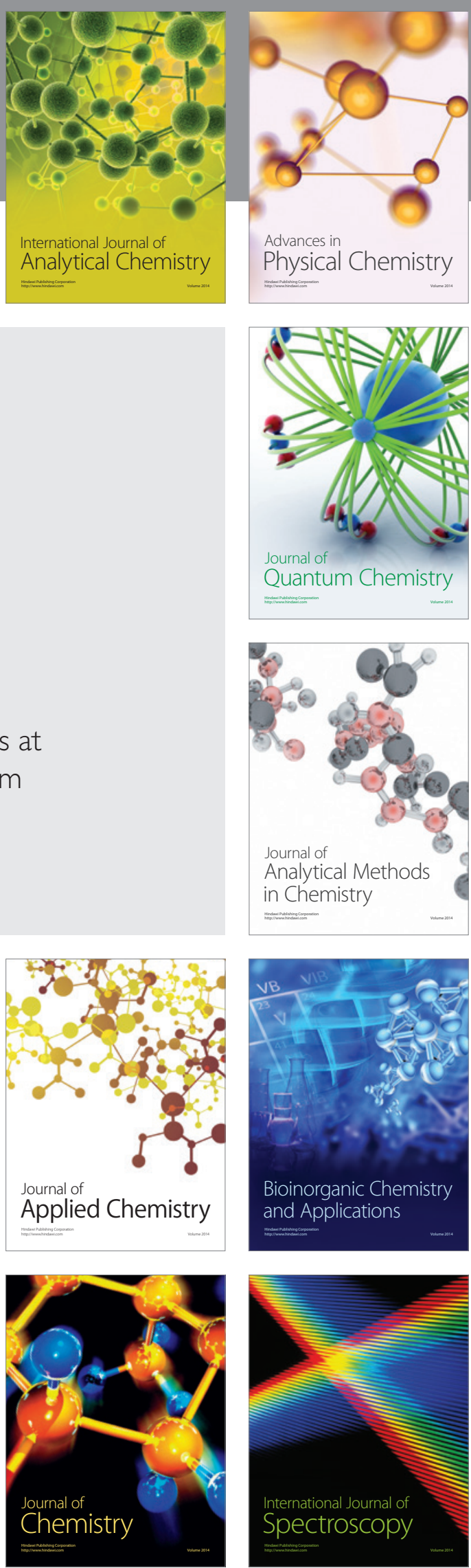